\title{
Faddists, enthusiasts and Canadian divas: broadcasting quotas and the supply response *
}

\author{
Martin Richardson $^{\dagger}$ and Simon Wilkie
}

March 2014

\begin{abstract}
$\underline{\text { Abstract }}$
This paper constructs a model of the recorded music market to investigate the consequences of local content requirements in broadcasting for the 'internationalization' of domestic music. We model the entry decisions of bands, the contracting decisions of record companies, the airplay decisions of radio stations and the radio listening and recording purchasing decisions of consumers. We show that, through the entry decisions of bands, a local content quota leads, perversely, to the increased internationalization of domestic music. A quota that also requires increased broadcasting of 'new' music yields an additional welfare loss but does nothing to a record company's incentives to sign up new bands.
\end{abstract}

Keywords: recorded music, local content, radio broadcasting, cultural quotas JEL Classifications: F13, L82, Z11

\footnotetext{
"We are grateful to seminar participants at the ANU, Strathclyde University, UCD and the Universities of Bielefeld, Kiel, Melbourne, Tasmania and Tübingen, and to participants at the 2012 APTS meetings, the Fall 2012 MWIEG meetings and the September 2012 ETSG; the usual disclaimer applies. We are also grateful for the financial support of the Australian Research Council through ARC grant DP0665477. Richardson thanks the UCD Geary Institute at University College Dublin and the Department of Economics at the University of Tübingen for their hospitality whilst this paper was being completed.

${ }^{\dagger}$ Richardson: Research School of Economics, College of Business and Economics, The Australian National University, Canberra, ACT 0200, Australia. Corresponding author.

$\$$ Wilkie: Department of Economics, Dornsife College of Letters, Arts and Sciences, University of Southern California, Los Angeles CA 90089-0253, USA.
} 


\section{Introduction}

Many countries prevent domestic broadcasters from freely choosing the proportions of international and 'domestic' content that they broadcast. Why is this done? Mas-Colell (1999) draws a useful distinction between "protection of national cultural production" and "protection of the production of national culture." The former is protection designed to maintain the existence of a particular industry, be it sound recording or movie-making and, as Mas-Collel suggests, it is difficult to see why the case for such protection is much different to the case for preserving shoe-making, car assembly or any other sector of the economy. The second term, however, refers to policies designed to, "promote the availability and consumption of [cultural goods] transmitting "Spanish", "French" or "Catalan" content: language, historical episodes, costumes, traditions, and the like." While the former is certainly cited by proponents of cultural protection, their principal arguments are of this latter sort: that cultural industries ${ }^{1}$ should be protected to save unique aspects of the local culture and identity and to foster global cultural 'diversity'. 2

The primary way in which broadcasting quotas might be used to achieve these goals is that being exposed to domestic music on the radio leads consumers to buy more such recordings. But a local content requirement constrains radio stations from choosing the airplay mix they prefer and so might impact on welfare through distorting this mix. Furthermore, the requirement may not bind on all genres. It will be particularly relevant where there is a greater preference for international content and one might anticipate that it

\footnotetext{
${ }^{1}$ The scope of industries that might be considered 'cultural' is vast, including food industries, protected under geographical indications legislation as well as more directly. Gordon and Meunier (2001) (p.30) cite the following position of one French commentator: "McDonald's ... commercial hegemony threatens our agriculture and its cultural hegemony insidiously ruins alimentary behaviour - both sacred reflections of the French identity."

2 This is by no means an uncontroversial proposition. It finds an extravagant expression in the words of exFrench President Mitterand, cited at p.1147 of Acheson and Maule (2006): "Creations of the spirit are not just commodities... What is at stake is the cultural identity of all our nations... A society which abandons to others the way of showing itself, that is to say the way of presenting itself to itself, is a society enslaved." By contrast, Revel (2003) perceives the French position as being essentially one of anti-Americanism and writes, "[t]he idea that a culture can preserve its originality by barricading itself against foreign influences is an old illusion that has always produced the opposite of the desired result. Isolation breeds sterility."
} 
will induce a shift in airplay away from international providers of those genres towards domestic artists in the same genre. Finally, a positive link between airtime and recording sales means a binding quota will induce entry by content providers into these constrained genres. Thus a local content quota might lead to the increased 'internationalization' of domestic music: Celine Dion, Shania Twain, Avril Lavigne and other Canadian singers might be considered essentially indistinguishable from U.S. artists. ${ }^{3}$

To model this policy instrument fully requires a setting in which listening to radio airplay affects record purchasing decisions and in which both the entry decisions of artists and the contracting decisions of record companies are considered. There is an extensive literature on the economic analysis of broadcasting, discussed more fully in Richardson and Wilkie (2013), but few authors address the issues focused upon here. In particular, we are not aware of any literature that formally models the artist/record company/radio station/consumer interaction. This paper analyses the consequences of a local content requirement in radio broadcasting when entry decisions of artists are endogenous. To do so, it constructs a model of the market for recorded music, integrating consumers (as both radio listeners and purchasers of recordings), radio stations, record companies and content providers ('bands'). In any genre there is an endogenous set of new domestic bands that could be contracted by a record company and some (endogenous) subset is, in fact, so contracted. Record companies extract record sales revenues and rents (from activities like concerts) from contracted bands for up to two periods; surviving bands then go off-contract and retain such income themselves. Genre-specific radio stations choose the airplay mix

\footnotetext{
${ }^{3}$ Hence our titular reference. Our first encounter with the term 'Canadian divas' was in an online opinion piece of Paul Krugman's suggesting that, "Boston residents who indulge their taste for Canadian divas do undermine the prospects of local singer-songwriters and might be collectively better off if local radio stations had some kind of cultural content rule" Krugman (1999). He goes on to note that, "there is a very fine line between such arguments for collective action and supercilious paternalism, especially when cultural matters are concerned".
} 
between new and established bands to maximize the listening time of their audience (in order to sell advertising time ${ }^{4}$ ) and consumers only buy the recordings of bands aired on the radio.

We then consider the imposition of a local content quota in broadcasting - one that just specifies an upper limit on the share of airtime devoted to international music - in this setting and derive its steady state effects on entry decisions and, importantly, welfare. Such quotas are typically justified on the grounds of thwarting the 'internationalization' of music, but we show that they can have exactly the opposite effect by inducing a shift in the pattern of band entry into 'international' genres. Nevertheless, we show that a mild quota ${ }^{5}$ will be welfareimproving in this model, for (inter alia) a novel reason: it raises the profitability of successful domestic bands and thus encourages entry by new domestic entrants, the increased diversity of which appeals to some consumers. In practice, some countries have refined their quotas to remedy a perceived problem with the simple quota: the latter can be (and is, in our model) met by just increasing the airplay of established domestic bands and thus appears to do little for new talent. ${ }^{6}$ We discuss the consequences of such a modification and show that, while the addition of a 'new' band component decreases the total amount of radio listening time by consumers (yielding a welfare loss), it does nothing to incentives to sign up new bands. A number of economists have looked at radio broadcasting (e.g. Coase (1966), Berry and Waldfogel (1999a, Berry and Waldfogel (1999b), Anderson and Coate (2005) and Rogers and Woodbury (1996)). There is a long literature addressing the question of optimal program diversity and its relationship to market structure (see, for example, Doyle (1998) and Richardson (2006)) but in the context of models in which a broadcaster chooses its

\footnotetext{
${ }^{4}$ Mangani (2003) considers a model of broadcasting in which programs differ along both a vertical and a horizontal dimension and in which profit maximisation and audience maximisation are different things. This is not the case here.

5 We use 'mild' to describe a quota that is just binding in a genre.

${ }^{6}$ France and Australia, for example, require that a specified fraction of the local content quota must be met by the playing of 'recent' recordings. "French music radio stations must broadcast a minimum of $40 \%$ French music (50\% of which must be dedicated to "new" French artists)." American University ICT Database (2001). For more on the prevalence of local content requirements in broadcasting see the Appendix to this paper, available on request.
} 
programming mix from some spectrum. There is a substantial policy-oriented literature discussing cultural quotas and related issues at an informal level (see, by way of example, Acheson and Maule (1990) and Jacobsen (2000)) but only a few recent papers (such as Francois and van Ypersele (2002) and Bala and Long (2005)) construct formal models of cultural protection. These are 'big picture' models of cultural goods, considering whether there might be something distinctive about the production (Francois and van Ypersele) or the consumption (both papers) of such goods that gives rise to novel arguments for protection. Our paper focuses more specifically on a particular sector and a particular policy instrument.

Some papers have looked explicitly at broadcasting quotas (Crampes and Hollander (1999), Owen and Wildman (1992) and Richardson (2006)) but none share our focus. Perona (2010) articulates explicitly the suggestion made above that a simple quota can be met just by putting established domestic artists on higher rotation but his model focuses on the decisions of radio stations regarding which set of genres to broadcast. Our scope is rather different, looking at the decisions of suppliers of content - bands and recording companies - as well as the broadcasting choices of radio stations. His "loss of diversity" result is from the broadcasting of fewer genres; ours is from the pattern of induced entry into genres.

Section 2 of the paper lays out our model, section 3 explains the timing of actions and section 4 exposits the laissez-faire, no-quota equilibrium of the model. Section 5 analyses the impacts of local content quotas, a further section considers the robustness of the analysis and a final section concludes.

\section{The Model}

We consider a model with four sets of actors: bands, record companies, radio stations and consumers. The model is effectively an overlapping three-period model. We consider each set of actors in turn. 


\section{i. Bands}

We make a small country assumption: there is a fixed number of foreign bands all of which are, by definition, 'successful' and may be either on- or off-contract with foreign record companies - all revenues and rents earned by foreign bands accrue offshore. There is a large number of potential new domestic bands indexed by $j=1,2, \ldots$ that might enter into genre $g$; an endogenous subset $M_{g}$ actually does so.

New bands incur a fixed cost $F_{B}$ to enter a genre $g \in G=\{1,2, \ldots, G\}$ and may be approached by record companies and contracted. In their $1^{\text {st }}$ period bands make record sales that depend positively on their radio airtime but earn nothing from this, as they are under contract to a record company. In any genre, some new entrants will fail and exit while others will succeed and survive into the next period. Successful bands not only sell records but generate a rent each period, representing surplus from concert revenues, T-shirt sales and so forth. In a band's first period of success this, too, accrues to the record company. There is some probability 1- $h$ of exit for a band after one period of success (under contract) so with probability $h$ a successful band in its $2^{\text {nd }}$ period goes on to become a successful band in its $3^{\text {rd }}$ (and final) period, when any rents accrue to the now "off contract" band. So in any genre $g$ there will be $n_{g} *$ successful foreign bands, $n_{g_{2}}\left(n_{g 3}\right)$ successful domestic bands on (off) contract and $n_{g 1}$ new domestic entrants, for a total of $N_{g} \equiv N_{g s}+n_{g 1} \equiv\left(n_{g} *+n_{g 2}+n_{g 3}\right)+n_{g 1}$ bands.

\section{ii. Record Companies}

We focus only on domestic record companies (or autonomous domestic affiliates of international companies. $)^{8}$ Each of an exogenous number of record companies incurs a fixed cost in period one, $F_{1}$, for managing a new band (which covers recording and promotion

\footnotetext{
7 By "off-contract" we simply mean that bands themselves capture a larger share of the surplus they generate, normalised to one for convenience. Successful bands still remain with record companies in practice and this simplification is intended just to capture the idea that the financial rewards to bands are postponed until after they are demonstrated successes.

${ }^{8}$ In practice the surplus generated by foreign artists will be a factor in determining record company attitudes towards broadcasting quotas, but here we focus solely on their positions vis-à-vis their domestic artists.
} 
expenditures) and a fixed cost in period two, $F_{2}$, for managing a successful band that is still on contract. Each record company specializes in a particular genre (so our record companies can alternatively be thought of as independent units within record companies): there is a oneto-one mapping between the set of record companies and the set of genres. ${ }^{9}$

A record company will consider the set of new entrant bands in its genre $\left(M_{g}\right)$, choose a number of them to sign up $\left(n_{g 1}\right)$ and offer them a contract that involves a payment to the band in return for the record company being entitled to all revenues from the band for its first two periods: record sales less $F_{1}$ in the band's first period and the band's second period record sales and rents (if successful) less $F_{2}$. Because bands commit to a genre before a contract is signed and because each genre has a single record company in it, so all surplus from the relationship can be extracted by the record company. We assume bands have an outside option valued at zero; hence the equilibrium contract offer to a band is zero. ${ }^{10}$ Nevertheless, every new band costs the record company $F_{1}$ to record and promote and it will seek to make money particularly on those bands that subsequently succeed. A record company then records its new artists and presents and promotes these bands to radio stations.

\section{iii. Radio Stations}

As our focus in this analysis is on the responsiveness of producers - bands and record companies - to cultural quotas, we do not model the decision-making of radio stations completely. Each of $K_{g}$ (endogenous) radio stations incurs an entry cost $F_{s}$ and specializes in genre $g$. Each station's effective objective is to maximize the time its listeners devote to listening to it - enabling it to sell more (unmodeled) advertising - and this entails maximizing the welfare of its audience, insofar as it can. The station has a fixed endowment of airtime,

\footnotetext{
${ }^{9}$ This is a significant assumption needed to make the model tractable and its impact is discussed in $s 6 i$ of the paper.

${ }_{10}$ One might consider that a band could be offered less than this: it could self-fund some of $F_{t}$ either directly or through borrowing. But the unobservability of a band's quality makes the latter infeasible (in the case where bands differ in quality) and, if bands have zero assets, the former is also infeasible. We take the 2-period contract as exogenous to capture an observed feature of reality.
} 
normalized to one, to allocate to bands and we assume it faces a two-stage problem in this decision: first it chooses the allocation of airtime between successful, established bands and new entrants and then it decides how much of each of these allocations to devote to each relevant band. We assume that each station receives $\alpha$ in advertising revenue per unit of listener time it attracts to its programming. ${ }^{11}$

\section{iv. Consumers}

Two types of consumer derive utility from a particular genre ${ }^{12}$ of music from two sources: listening to it on the radio and buying a recording. Each of the $L$ consumers, normalized to one henceforth, has lexicographic preferences over the genres so that they are divided across the genres that are aired and a fraction $\lambda_{g}$ listen to genre $g$ (so $\sum_{g} \lambda_{g}=1$.) All consumers consider new music and established music to be differentiated generically, insofar as purchasing recordings is concerned. Within genre $g$ some consumers - an exogenous fraction $\mu_{g}$ - are 'enthusiasts' or 'purists': they value diversity within their preferred genre and derive utility both from hearing music on the radio and from purchasing the recordings of their favorite new artist. The remaining fraction $1-\mu_{g}$ of a genre's consumers are 'faddists': they derive utility from being part of the latest trend and buying the recordings only of successful artists, domestic and foreign. Both kinds of consumers' problems boil down to which recording to buy and how much time to devote to radio listening.

We assume that all consumers in any genre are equally split across the (identical) radio stations in the genre and, purely for reasons of tractability, have identical Cobb-Douglas preferences with respect to radio listening - as opposed to recording purchases, where faddists and enthusiasts differ - defined over the mix of airtime devoted to new entrant bands

\footnotetext{
11 So a radio station broadcasts throughout the day - one unit of time - and splits that between new and established bands. A consumer listens to the radio for some period of time and it is assumed implicitly that that is randomised across the day so that a consumer will hear new and established bands in the same ratio in which they are played by the radio station.

12 Berry and Waldfogel (1999b) note that there is a positive and significant relationship between the number of different formats offered in radio broadcasting - our genres - and the share of the population that actually listens to the radio, suggesting that consumers do, indeed, have genre preferences.
} 
in the genre and to established, successful artists. In particular, the utility derived by a consumer in genre $g$ from listening to the radio depends on $A_{g}$ (the airtime devoted in genre $g$ to new bands), $A_{g s}$ (the airtime devoted to successful, established bands, whether domestic or foreign), $t_{g}$ (the consumer's choice of time to devote to radio listening) and $w$ (the consumer's opportunity cost of time spent listening to the radio), all in the fashion expressed in (3) below.

But the consumer also chooses to purchase the recordings of their favorite band and derives additional utility from that. We model this as a discrete choice in the following way: a consumer places a value $v_{g j}$ on purchasing the recording of band $j$ in genre $g$ and this value depends on the band's share of radio airtime, $a_{g j}$, the (common) price of the recording $p^{13}$, and a random idiosyncratic component $\varepsilon_{g j}$. Thus $v_{g j}=a_{g j}+\varepsilon_{g j}-p$ and we assume the idiosyncratic values are independently and identically distributed according to the double-exponential distribution function:

$$
F(\varepsilon)=\exp \left\{-e^{-\varepsilon}\right\}
$$

We can then calculate the probability, denoted $x_{g j}$, that a particular new band $j$ yields the maximum utility across all new bands in the genre for an enthusiast consumer:

$$
x_{g j}=\frac{\exp \left\{a_{g j}\right\}}{\sum_{k=1}^{n_{g 1}} \exp \left\{a_{g k}\right\}}
$$

Note from this that, if all bands had the same airtime, each would be equally likely to be a consumer's favorite band (with probability $1 / n_{g_{1}}$.)

The expression for $x_{g j}$ indicates a consumer's likelihood of purchasing the recording of band $j$ in genre $g$. But consumers also derive utility from hearing music on the radio, as discussed, so the problem facing the consumer who buys the recording of artist $j$ is to choose $t_{g}$ to maximize their total consumer utility given by:

\footnotetext{
${ }^{13}$ We do not model the setting of uniform prices in this sector, but take it as a long-standing feature of the industry (if puzzling to economists: see Shiller and Waldfogel (2011). However, see Richardson and Stähler (2013) for one possible asymmetric information based explanation.)
} 


$$
U_{g}=\ln \left(t_{g}\right)\left(A_{g}^{\beta} A_{g s}^{1-\beta}\right)+\left(1-t_{g}\right) w+v_{g j}
$$

For radio stations, the only choice variable is the airtime devoted to each band and we assume that they give each new (established) band an equal share of the total airtime the station itself chooses to devote to new (established) bands. So the radio station's choice sans quota - is how much of its airtime to devote to new music and how much to devote to established music; within each of these allotments it simply divides up the time available equally across all relevant bands. ${ }^{14}$

Figure One presents a summary of these relationships within a genre.

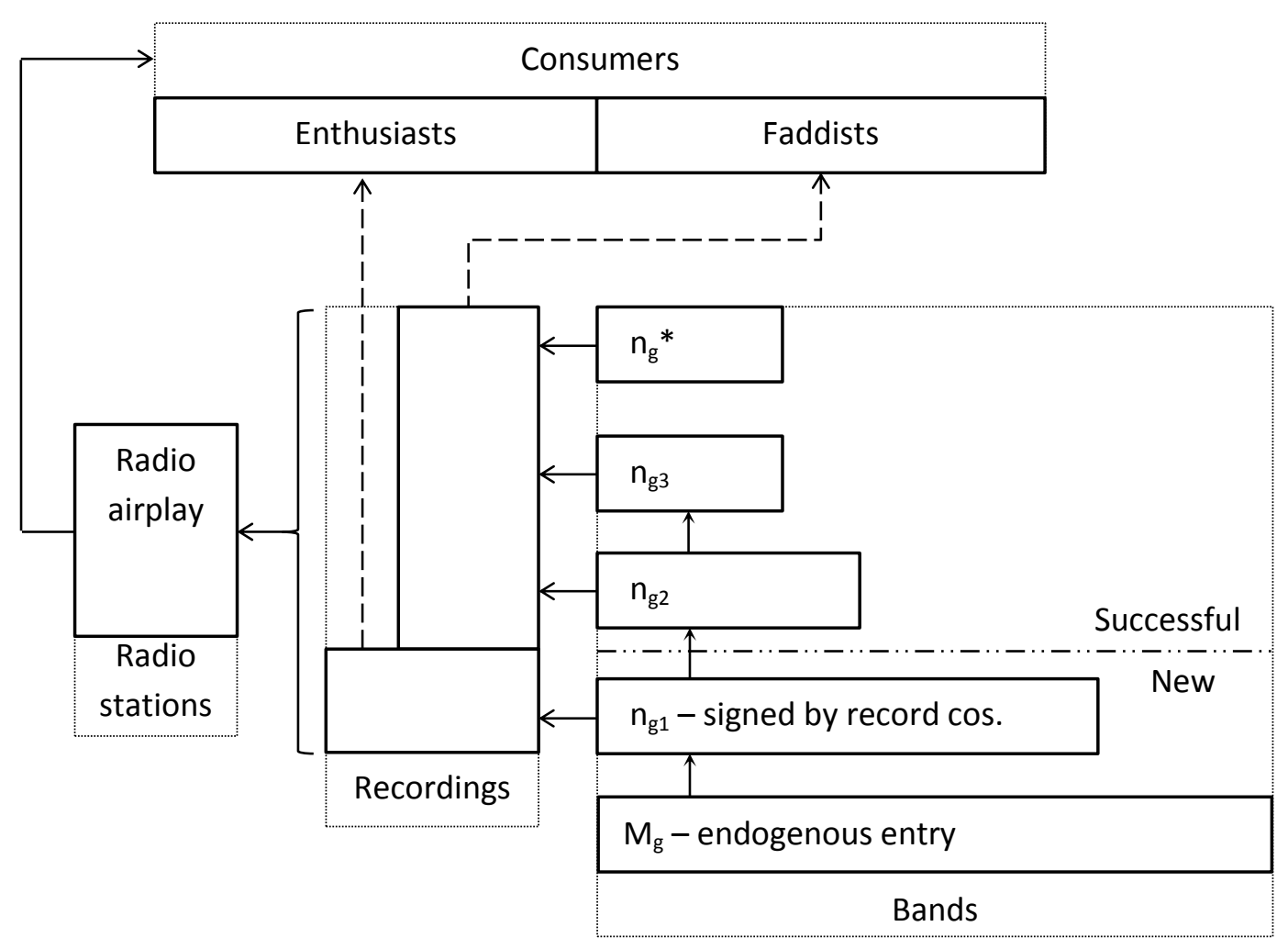

Figure One: Schematic representation of model structure

\footnotetext{
14 If consumers have any preference for diversity within the $A$ and $A_{s}$ allocations (so would prefer to hear each of 20 songs once rather than hear the same song 20 times), as in Perona (2010), then it would be optimal for the radio stations to behave as supposed here. We do not explicitly model this, however: the actual sub-allocation here is strictly a matter of indifference to radio stations.
} 


\section{3. $\underline{\text { Timing }}$}

We assume that before each period $t$ the government imposes any domestic music quota; all potential new bands then choose their genre; they present to the genre-specific record company and are either contracted or not; contracted bands are recorded and presented by the record companies, along with established, successful bands, both domestic and international, to radio stations who choose how to allocate airtime to these recordings; consumers devote time to listening to a radio station, given these allocations, and purchase recordings of either new or established artists. Then some bands 'succeed' and become established, earning rents for periods $t+1$ and (with survival probability $h$ ) $t+2$ before disappearing, while unsuccessful new bands from $t$ fail and disappear before $t+1$. We consider only steady-state equilibria.

\section{No quota}

i. Agents' choices

Consider first the decisions of radio stations. A genre-specific station in $g$ knows that a fraction $\mu_{g}$ of its $\lambda_{g} L / K_{g}$ consumers choose $t_{g}$ to maximize (3) and the rest choose $t_{g F}$ to maximize an analogous expression and so choose their listening times so that:

$$
\begin{gathered}
A_{g}^{\beta} A_{g s}^{1-\beta}=t_{g} w \\
A_{g}^{\beta} A_{g s}^{1-\beta}=t_{g F} w
\end{gathered}
$$

To maximize $t_{g}$ and $t_{g F}$, the times consumers spend listening to the radio, the station should thus choose its mix to maximize the LHS of each equation in (4), subject to the constraint that the overall airtime shares sum to one. So, in equilibrium, $t_{g}=t_{g F}$.

The profitability of a radio station depends directly on its audience size. So radio stations choose their genre such that, given the distribution of other stations, no alternative genre is more profitable. In genre $g$ there are $\mu_{g} \lambda_{g}$ enthusiast consumers each devoting time $t_{g}$ to listening to the radio and $\left(1-\mu_{g}\right) \lambda_{g}$ faddists devoting time $t_{g F}$ to radio listening so that the 
total listening time of fans in genre $g$ is $\left\{\mu_{g} t_{g}+\left(1-\mu_{g}\right) t_{g F}\right\} \lambda_{g}$. Supposing that genre $g$ attracts $K_{g}$ stations, the profit of each is:

$$
\pi_{s g}\left(\frac{\lambda_{g}}{K_{g}}\right)=\frac{\alpha \lambda_{g}}{K_{g}}\left\{\mu_{g} t_{g}+\left(1-\mu_{g}\right) t_{g F}\right\}-F_{s}=\alpha \frac{\lambda_{g} t_{g}}{K_{g}}-F_{S}
$$

where the second equality follows in equilibrium, wherein $t_{g}=t_{g f}$.

Rolling back to the decisions of the record companies, they take the number of radio stations in their genre as given. All recordings sell for a price $p$ and the record company retains all such earnings for new bands, by virtue of its contract with each band. Expected recording sales revenue from a typical new band in genre $g$ is:

$$
S_{g j}=p x_{g j} \mu_{g} \lambda_{g}
$$

where $x_{g j}$ is given in (2).

On top of new band record sales revenues, record companies also receive record sales and a genre-specific rent of $\varphi R_{g}$ from a successful band in genre $g$ for one period - where $\varphi$, discussed below, is less than one - and this is all discounted by the common discount factor $\delta$. In steady state, new entrant band numbers and successful band numbers (in expectation) are constant so the record company's maximand is:

$$
\pi_{g}=p \lambda_{g}\left[\mu_{g} \sum_{k=1}^{n_{g 1}} x_{g k}+\left(1-\mu_{g}\right) \sum_{k=1}^{n_{g 2}} x_{g s k}\right]+n_{g 2} \varphi R_{g}-n_{g 1} F_{1}-n_{g 2} F_{2}
$$

Finally, we turn to the entry decisions of bands. The essential choice for them is whether or not to enter (i.e. to form a band that seeks a record contract.) In genre $g$ there are $M_{g}$ bands vying for recording contracts, which are granted only to $n_{g 1} \leq M_{g}$ of the bands. All bands are ex ante identical so a band's probability of an initial contract is simply $n_{g l} / M_{g}$. If $f\left(n_{g 1}\right)$ new entrants succeed (discussed more fully below) then the probability of success, conditional on being contracted, is $f\left(n_{g 1}\right) / n_{g l}$. With the probability of surviving from period 2 to period 3 being $h$, the overall ex ante probability of an entrant making it to period 3 (and so going off-contract) is then $\left(n_{g 1} / M_{g}\right)\left(f\left(n_{g 1}\right) / n_{g 1}\right) h$ or $\left(f\left(n_{g 1}\right) / M_{g}\right) h$. An entrant incurs a fixed cost 
of $F_{B}$ initially and, if it turns out to be unsuccessful, it will then receive zero (its losses being borne by the record company), so its decision is driven solely by its payoff in the case of success. If a band enters it anticipates that it will, if it survives to period 3, receive $\varphi R_{g}$ plus record sales revenues (of $\left.\left(p \lambda_{g}\left(1-\mu_{g}\right)\right) x_{g 2 j}\right)$ in that period. In equilibrium, then, a band will be indifferent about entry only if its expected return is zero. Denoting by $G^{*}$ the set of genres profitable for radio stations, our equilibrium condition is:

$$
\frac{f\left(n_{g 1}\right)}{M_{g}} h\left(p \lambda_{g}\left(1-\mu_{g}\right) E\left(x_{g 3}\right)+\varphi R_{g}\right) \delta^{2}=F_{B} \quad \forall g \in G^{*}
$$

We now say a little more about the per-band rent in a genre, $R_{g}$. We assume that this is an increasing function of the faddist consumer demand for that genre, $\lambda_{g}\left(1-\mu_{g}\right)$, and a decreasing function of the number of successful bands in that genre, $N_{g s}=n_{g 2}+n_{g 3}+n_{g} *$. To be specific, we suppose that the aggregate rent in $g$ is a linear function of consumer numbers, $c_{g} \lambda_{g}\left(1-\mu_{g}\right)$ for some constant $c_{g}$, and that the per-band rent is then simply their record-sales weighted share of this. So we assume, using $x_{g s}$ to denote the expected record sales of a successful domestic band, that

$$
R_{g}=x_{g s} \lambda_{g}\left(1-\mu_{g}\right) c_{g} \forall g \in G^{*}
$$

But this rent is a transfer from faddist consumers buying T-shirts, for example, or attending concerts, and represents the aggregate value placed by such consumers on these services. It costs the bands real resources to provide these services and we suppose simply that this cost is some fraction of the consumer valuation. Consequently, if consumers pay $R_{g}$ for services they value at that price, only a fraction $\varphi \in[0,1]$ accrues to bands as rent. Then equilibrium condition (8) becomes:

$$
\frac{f\left(n_{g 1}\right)}{M_{g}} h \lambda_{g}\left(1-\mu_{g}\right) E\left(x_{g 3}\right)\left(p+\varphi c_{g}\right) \delta^{2}=F_{B} \quad \forall g \in G^{*}
$$




\section{ii. Welfare}

Free entry by bands and radio stations ensures zero expected profits for them, ${ }^{15}$ leaving record company profit and consumer surplus as the components of national welfare. For record companies we have profit as described in (7) in any period.

Following Anderson and de Palma (1992), consumer surplus in genre $g$ is:

$$
C S_{g e}=\mu_{g} \lambda_{g} \ln \left(\sum_{j=i}^{n_{g 1}} \exp \left(a_{j}+T-p\right)\right)=\mu_{g} \lambda_{g}(T-p) \ln \left(\sum_{j=1}^{n_{g 1}} \exp \left(a_{j}\right)\right)
$$

for enthusiast consumers and, for faddists for all successful bands ${ }^{16}$ :

$$
C S_{g f}=\left(1-\mu_{g}\right) \lambda_{g}\left(T^{f}-p\right) \ln \left(\sum_{j=1}^{N_{g s}} \exp \left(a_{j}\right)\right)
$$

with $T \equiv\left[\ln t_{g}\left(A_{g}^{\beta} A_{g s}^{1-\beta}\right)+\left(1-t_{g}\right) w\right]$ and $T^{f}$ defined isomorphically. So aggregate consumer surplus in genre $g$ can be written:

$$
\begin{gathered}
C S_{g}=C S_{g e}+C S_{g f}= \\
\lambda_{g}\left[\mu_{g}(T-p) \ln \left(\sum_{j=i}^{n_{g 1}} \exp \left(a_{j}\right)\right)+\left(1-\mu_{g}\right)\left(T^{f}-p\right) \ln \left(\sum_{j=i}^{N_{g s}} \exp \left(a_{j}\right)\right)\right]
\end{gathered}
$$

In sum, in any period in steady state we have welfare generated by genre $g, W_{g}$, as:

$$
\begin{gathered}
W_{g}=\lambda_{g}\left[p \mu_{g} \sum_{k=1}^{n_{g 1}} x_{g k}+\left(1-\mu_{g}\right)\left(p+\varphi c_{g}\right) \sum_{k=1}^{n_{g 2}} x_{g s k}\right]-n_{g 1} F_{1}-n_{g 2} F_{2}+ \\
\lambda_{g}\left[\mu_{g}(T-p) \ln \left(\sum_{j=1}^{n_{g 1}} \exp \left(a_{j}\right)\right)+\left(1-\mu_{g}\right)\left(T^{f}-p\right) \ln \left(\sum_{j=i}^{N_{g s}} \exp \left(a_{j}\right)\right)\right]
\end{gathered}
$$

Note that if each successful band gets the same airtime, $a$, then $C S_{g f}$ simplifies down to (1$\left.\mu_{g}\right) \lambda_{g}\left(T^{f}-p\right)\left[\ln \left(N_{g s}\right)+a\right]$.

\footnotetext{
${ }^{15}$ As noted previously, we do not model the advertising side of the radio stations' problem explicitly. But, in terms of welfare, we assume that the advertising market is competitive and that advertisers extract no surplus from advertising.

${ }^{16}$ Note that the rent transfer does not enter into consumer welfare as it represents the valuation consumers place on the non-recording services received from successful bands and so washes out.
} 


\section{iii. The nature of band 'success'}

We have assumed that, at the end of a period, only some fraction of new entrants in genre $g$ will survive. The Appendix discusses a number of alternative ways in which this success might be modeled. For the remainder of the paper we take the case in which success is entirely exogenous: the number of successful bands is a known, deterministic function of the number of new entrants:

$$
n_{g 2}=f\left(n_{g 1}\right), \quad f(0)=0, f^{\prime} \in(0,1), f^{\prime \prime} \leq 0
$$

As only a fraction $h$ of period 2 successful bands go on to be successful bands off-contract in period 3, we have $n_{g 3}=h n_{g 2}=h f\left(n_{g 1}\right)$ so that the total number of successful bands in genre $g$ in any period is given in steady state by $N_{g s}=(1+h) f\left(n_{g 1}\right)+n_{g}{ }^{*}$.

In period one the record company in genre $g$ signs up $n_{g l}$ bands. But, because all new bands in a genre sign with the same record company, so all revenues from new band sales accrue to the same company. As record sales are expressed in terms of market shares, so the record company's share of new band sales is always one. Of course, $n_{g 2}=f\left(n_{g 1}\right)$ of these bands then succeed and go onto period two, and this is where the choice of $n_{g 1}$ impacts potential record company profits. With $n_{g 2}$ deterministic, so too is per-band airtime and the record company's profit is:

$$
\pi_{g}=k_{1}+k_{2} E\left(n_{g 2} x_{g 2}\right)-n_{g 1} F_{1}-n_{g 2} F_{2}
$$

where $k_{1}=p \mu_{g} \lambda_{g}$ and $k_{2}=\left(1-\mu_{g}\right)\left(p+\varphi c_{g}\right) \lambda_{g}$ are positive constants. That is, denoting by $a_{g s}$ the airtime devoted to a successful band in genre $g$,

$$
\begin{aligned}
\pi_{g}\left(n_{g 1}\right)=k_{1} & +k_{2} f\left(n_{g 1}\right) \frac{\exp \left(a_{g s}\right)}{(1+h) f\left(n_{g 1}\right) \exp \left(a_{g s}\right)+n_{g}^{*} \exp \left(a_{g}^{*}\right)}-n_{g 1} F_{1} \\
& -f\left(n_{g 1}\right) F_{2}
\end{aligned}
$$




\section{iv. Equilibrium}

Solving a radio station's problem yields:

$$
A_{g s}=1-\beta, \quad A_{g}=\beta
$$

Deviations from this ratio will reduce consumer welfare and therefore reduce their listening time devoted to the radio.

As $t_{g}=t_{g F}$ in equilibrium so expressions (4) and (18) imply that $t_{g}=\beta^{\beta}(1-\beta)^{1-\beta} / w$ so total listening time is $\beta^{\beta}(1-\beta)^{1-\beta} \lambda_{g} / w$, earning the station total advertising revenues of $\alpha \beta^{\beta}(1-\beta)^{1-}$ ${ }^{\beta} \lambda_{g} / w$. Thus (5) becomes:

$$
\pi_{s g}\left(\frac{\lambda_{g}}{K_{g}}\right)=\alpha \frac{\lambda_{g}}{K_{g}} t_{g}-F_{s}=\frac{\alpha}{w} \frac{\lambda_{g}}{K_{g}}\left(\beta^{\beta}(1-\beta)^{1-\beta}\right)-F_{s}
$$

We ignore the integer constraint on the number of radio stations and treat it as a continuous variable. Consequently our free entry condition for radio stations becomes, denoting by $G^{*}$ the set of weakly profitable genres,

$$
\alpha \frac{\lambda_{g}}{K_{g}} t_{g}=F_{s} \Rightarrow K_{g}=\alpha \frac{\lambda_{g}}{F_{s}} t_{g}=\frac{\alpha}{w} \frac{\lambda_{g}}{F_{S}}\left(\beta^{\beta}(1-\beta)^{1-\beta}\right) \forall g \in G^{*}
$$

From this, note that the more popular the genre, ceteris paribus, the larger will be the number of radio stations operating in that genre: $K_{g}$ is increasing in $\lambda_{g}$.

The problem facing a record company in genre $g$ is,

$$
\max _{\left\{n_{g 1}\right\}} \pi_{g}\left(n_{g 1}\right)=k_{1}+k_{2} \frac{f\left(n_{g 1}\right)}{\left\{(1+h) f\left(n_{g 1}\right)+n_{g}^{*}\right\}}-n_{g 1} F_{1}-f\left(n_{g 1}\right) F_{2}
$$

This yields a FOC and SOC as follows:

$$
\begin{gathered}
\frac{d E\left(\pi_{g}\right)}{d n_{g 1}}=k_{2} \frac{f^{\prime}\left(n_{g 1}\right) n_{g}^{*}}{\{.\}^{2}}-\left(F_{1}+f^{\prime}\left(n_{g 1}\right) F_{2}\right)=0 \\
\frac{d^{2} E\left(\pi_{g}\right)}{\left(d n_{g 1}\right)^{2}}=k_{2} n_{g}^{*} \frac{f^{\prime \prime}\left(n_{g 1}\right)\{.\}-2\left(f^{\prime}\left(n_{g}\right)\right)^{2}(1+h)}{\{.\}^{3}}-f^{\prime \prime}\left(n_{g 1}\right) F_{2} \leq 0
\end{gathered}
$$


The Appendix demonstrates that the solution to the record company's problem yields an optimal choice of $n_{g l}$ where the signs of partial derivatives are as shown:

$$
n_{g 1}=n_{g 1}(\underbrace{p, \lambda_{g}, \varphi c_{g}}_{(+)}, \underbrace{\mu_{g}, h, F_{1}, F_{2}}_{(-)}, \underbrace{n_{g}^{*}}_{(+/-)})
$$

For bands, with no quota $\mathrm{E}\left(x_{g s}\right)=1 / N_{g s}$ so (10) solves for $M_{g}$ as follows:

$$
\begin{aligned}
& \frac{f\left(n_{g 1}\right) \lambda_{g}\left(1-\mu_{g}\right)}{F_{B} N_{g s}}\left(p+\varphi c_{g}\right) \delta^{2} h=M_{g} \\
& \Rightarrow M_{g}=M_{g}(\underbrace{n_{g 1}, \lambda_{g}, \varphi c_{g}, \delta, h, p}_{(+)}, \underbrace{\mu_{g}, F_{B}, n_{g}^{*}}_{(-)})
\end{aligned}
$$

In many models of entry behind a fixed cost we observe that the laissez-faire solution leads to over-entry from a social perspective due to the well-known business-stealing effect. In this model, however, the 'entry' decision for new bands (in terms of being contracted etc.) is made by a record company for all the potential entrants. Any business stealing by a new band is pure cannibalization and so it will be taken into account when entry is determined. For this reason, there is no presumption in this model that there will be over-entry.

On the contrary, we can see that the laissez-faire solution in this model involves too few new domestic (and, consequently, subsequently successful domestic) bands. The record company chooses $n_{g 1}$ to maximize its own profits but welfare is the sum of profits and the consumer surplus of both faddist and enthusiast consumers. From (11) and (12):

$$
\begin{gathered}
C S_{g e}=\mu_{g} \lambda_{g}(T-p)\left(\ln \left(n_{g 1}\right)+\frac{A_{g}}{n_{g 1}}\right) \\
\Rightarrow \frac{d C S_{g e}}{d n_{g 1}}=\frac{\mu_{g} \lambda_{g}(T-p)}{n_{g 1}}\left(1-\frac{A_{g}}{n_{g 1}}\right)>0 \\
C S_{g f}=\left(1-\mu_{g}\right) \lambda_{g}\left(T^{f}-p\right)\left(\ln \left[n_{g}^{*}+(1+h) f\left(n_{g 1}\right)\right]+\frac{A_{g s}}{\{.\}}\right)
\end{gathered}
$$




$$
\Rightarrow \frac{d C S_{g f}}{d n_{g 1}}=\frac{\left(1-\mu_{g}\right) \lambda_{g}\left(T^{f}-p\right)(1+h) f^{\prime}\left(n_{g 1}\right)}{\left\{n_{g}^{*}+(1+h) f\left(n_{g 1}\right)\right\}}\left(1-\frac{A_{g s}}{\{.\}}\right)>0
$$

So, unsurprisingly, consumer surplus for all consumers is increasing in $n_{g 1}$ and the implication is that the laissez-faire solution involves too few bands from a social welfare perspective, as the record company ignores the impact on CS of its contracting decisions. An optimal intervention to correct this would be one that directly targets $n_{g l}$; that is, a subsidy to $F_{1}$, the fixed cost of contracting new bands.

We summarize these results in the following proposition:

Proposition 1: The laissez-faire equilibrium of this model involves

$i$. The radio broadcasting of new and established music in the proportion $\beta /(1-\beta)$ in every genre;

ii. Entry of radio stations into a genre in direct proportion to $\lambda_{g}$, the popularity of the genre in the listening public;

iii. The choice by a record company in a genre of the number of new bands to sign to contracts, where this number is increasing in the price of recordings, the popularity of the genre in the population, and the rents that accrue to bands in the genre; is decreasing in the proportion of the genre's consumers that are enthusiasts, the survival rate of successful bands and the record company's fixed cost of contracting bands, and is nonmonotonic in the number of foreign bands in the genre;

iv. The entry into the genre of a number of bands seeking contracts where that number is increasing in the price of recordings, the popularity of the genre in the population, the rents that accrue to bands in the genre, the number of new bands signed up by the record company, the band's discount factor and the survival rate of successful bands; and is decreasing in the proportion of the genre's consumers that are enthusiasts, the number of foreign bands in the genre and the fixed cost of entry by bands;

v. Too few contracted bands from an aggregate welfare perspective.

\section{A local content quota}

A simple ${ }^{17}$ local content requirement imposed on a genre $g$ will require stations in that genre to play domestic music in a certain proportion - equivalently, airtime devoted to foreign music must be less than some proportion of total airtime. Thus the quota is a constraint that $\sum_{m=1}^{n_{g}^{*}} a_{g m}^{*} \leq Q$ for some airtime level $Q$.

\footnotetext{
17 By which we mean a quota that draws no distinction between new and established domestic artists.
} 
As is shown more formally in the Appendix, a just-binding simple quota on foreign bands' airtime will, in the short run ${ }^{18}$, lead to an increase in the airtime devoted to successful domestic bands, with no consequences for the aggregate airtime split between new and established bands. As a consequence, nothing disturbs the free-entry condition governing radio stations in each genre. However, the increased airtime for successful domestic bands means higher expected record sales for such bands and thus higher expected profits for new bands in the affected genre. This induces immediate entry by new bands into that genre. In the medium run this entry of new bands will lead to an increased number of successful domestic bands in the genre who are on contract to record companies and, in the long run, this will flow through to the number of successful domestic bands off contract.

Turning to welfare, there is clearly a profit-increasing effect of a tighter quota. This occurs for standard profit-shifting reasons: given the fixed recording price, the quota shifts airtime to successful domestic bands and so increases domestic record sales and profits therefrom. As noted, there is no distortion of the optimal airtime mix but both $n_{g l}$ and $N_{g s}$ are increased by the quota.

Our expression for consumer surplus is now, noting that $T=T^{f}$ in equilibrium and that each new band gets the same airtime $1 / n_{g 1}$,

$$
\begin{gathered}
C S_{g}=\lambda_{g}(T-p)\left[\mu_{g}\left(\ln \left(n_{g 1}\right)+\frac{1}{n_{g 1}}\right)+\left(1-\mu_{g}\right) \ln \left(n_{g}^{*} \exp \left(\frac{Q}{n_{g}^{*}}\right)+(1+\right.\right. \\
\text { h) } \left.\left.f\left(n_{g 1}\right) \exp \left(\frac{A_{g s}-Q}{(1+h) f\left(n_{g 1}\right)}\right)\right)\right]
\end{gathered}
$$

Consequently there are conflicting effects on consumers of a tightening of the quota.

Enthusiast consumers are strictly better off: the quota induces entry of new bands and enthusiasts' welfare is increasing in the number of bands, $n_{g l}$, an effect that more than offsets their losses from lower airtime per band. These bands are signed up because the profitability

\footnotetext{
${ }^{18}$ Immediately the policy is imposed and before 'successful' band numbers can respond. That is, in the first period following the policy's imposition.
} 
of successful bands has increased. In many contexts, this kind of entry - induced at an earlier stage by the prospect of subsequent profits - will simply dissipate any subsequent rents and so is welfare-neutral, at best. But in this model enthusiast consumers benefit from an increased diversity of new bands, whether they subsequently succeed or not. For some faddist consumers, however, there is a welfare loss from the reduced airtime for foreign bands: consumers who purchase the recordings of foreign bands now get lower gains from such purchases. But that reduced airtime is now devoted to successful domestic bands, the number of which has increased and this benefits faddist consumers. The Appendix demonstrates that any simple quota that induces entry must raise the consumer surplus of faddist consumers overall; this is certainly the case for a mild (i.e. just-binding) quota.

Turning to other players, the quota has no effects on radio stations' entry decisions. But for bands a quota gives an incentive for entry into a constrained genre due to both the increase in expected third-period record sales - the proceeds of which accrue to the band and the increase in the number of bands signed in the genre. So there is an increase in the number of bands in the genre seeking contracts.

Now suppose that the economy as a whole is characterized by a variety of genres differing by foreign band concentration. Suppose that a common quota is imposed across all genres. ${ }^{19}$ The relative impact on one genre versus another will depend ultimately on the relative impact of the quota on expected record sales for successful bands across genres while it is the third-period manifestation of this that is of interests to bands in their entry decisions, it is the second-period occurrence that induces record companies to sign up more new entrant bands. A given quota will be more profitable in terms of raising domestic record sales the more binding it is on foreign acts i.e. the greater is the proportion of airtime devoted

\footnotetext{
19 Australia, however, has genre-specific quotas, with higher local content requirements in more popular genres. There are five categories of music and local content requirements range from $25 \%$ in the contemporary popular music format (and at least $25 \%$ of the local content must be "new": released in the previous 12 months) to 5\% in niche formats, such as jazz, with no "new" constraint.
} 
to foreign bands in the absence of a quota. Hence we see our "Canadian divas" effect: a sector-wide common quota induces greater entry of domestic bands seeking contracts in genres where foreign music is more concentrated.

We summarize these results in the following proposition:

Proposition 2: A simple local content quota in steady state in this model,

$i$. Will leave the radio airplay mix between new and established bands unaffected but will increase the share of airplay devoted to successful domestic bands;

ii. $\quad$ Will leave entry decisions by radio stations unaffected;

iii. Will increase both entry and contracting of domestic bands and thus the number of both new and successful domestic bands;

iv. Will lead to greater 'internationalization' of domestic music: a greater share of domestic music (both played by entrants and contracted bands and heard on the radio) is produced by bands in genres where international music is most prevalent;

v. Is welfare-improving if the quota is mild: just binding.

\section{i. A new-music quota}

As noted in the Introduction, a number of countries have introduced rather more complicated quotas that require not only that domestic music receive a greater share of radio airtime but that some proportion of this be allocated to 'new' domestic music. This is to prevent exactly the behavior just described: that a radio station meets the quota simply by playing more established domestic artists, rather than airing new ones. Such a quota has two components: a 'simple' quota as analyzed above combined with a requirement that more new music be played. ${ }^{20}$ In this sub-section we focus on the second of these two effects and, as all new entrant music in our model is generated by domestic bands, we consider a policy that requires an increase in $A_{g} / A_{g s}$.

If a policy is imposed that requires an increase in $A_{g}$ at the expense of $A_{g s}$ then this will reduce the overall time devoted to listening to the radio, by (4). Ignoring this change in $t_{g}$ for the moment, for given band numbers, the increase in $A_{g}$ has no effect on record

\footnotetext{
${ }^{20}$ In fact, the requirement can be met by playing new releases from established bands. Our model does not permit this possibility: implicitly bands here issue a single recording at the start of their lives and sell it for, potentially, three periods.
} 
company profits: the increase in airtime each band receives has no impact on their record sales as it is common to all bands in the genre and overall record sales are unchanged (at $\mu_{g} \lambda_{g}$.) The decrease in $A_{g s}$ will be shared across all successful bands, foreign and domestic, so every successful band will get reduced airtime. But the overall domestic share of record sales and rents will be unaffected by this and, again, total record sales are unaffected so the domestic record company is not impacted by this policy at all. Hence it signs no additional bands and there are no entry/exit consequences of the policy.

But welfare is impacted through the distortion induced in the radio airtime mix and the consequent reduction in airtime devoted to radio listening by consumers ${ }^{21}$. This distortion reduces the overall time devoted to listening to the radio so consumer surplus for all consumers falls. For a just-binding quota this effect is second-order, of course, but the reduction in listening time is reflected in exit by radio stations. If the quota affects some genres more than others then we will observe in this case an increase in the relative amount of domestic music broadcast: all stations broadcast more domestic content and exiting stations are those in genres where the quota binds most tightly i.e. those with a greater concentration of foreign artists.

Now, this quota involves the packaging of the policy just described with a simple quota, analyzed previously. Consequently, this quota when just-binding will be welfareimproving under the same circumstances and for the same reasons that a just-binding simple quota is welfare-improving. However, a non-marginal new-music quota will yield lower overall welfare than the equivalent simple quota.

We summarize these results in the following proposition:

\footnotetext{
21 In a richer model of advertising, this reduction in $t_{g}$ would also impact on the advertising market. In this model we will see a decrease in the number of radio stations in genre $g$ following the quota, as $t_{g}$ falls in (19). This is a feature of our model: consumers have no preferences across radio stations in a particular genre, as they are all identical, so when less time is devoted to listening to a genre it is reflected not in the listening time per station but in the total number of stations. This exit of stations has no welfare consequences of its own, due to the zero profit condition for station equilibrium.
} 
Proposition 3: In this model, a new-music quota in steady state will, beyond the effects of the simple quota,

i. Alter the radio airplay mix in favor of new (domestic) bands;

ii. Lead to lower airtime for every successful band, domestic or foreign, and increased airtime per new domestic band, both for each remaining radio station and in aggregate;

iii. Have no consequences for record sales;

iv. Lead to the exit of some radio stations;

v. Have no consequences for entry or the contracting of new domestic bands and thus for the number of both new and successful domestic bands;

vi. Lead to greater 'internationalization' of domestic music to the extent that it drives out radio stations in the most heavily affected genres: those that are most 'international';

vii. Reduce welfare at a greater rate than a simple quota when it becomes increasingly binding.

\section{Modeling choices and robustness}

i. Multiple record companies in each genre.

The assumption that each genre is characterized by a single record company buys us a great deal in terms of the tractability of the analysis by reducing the company's choice of the number of new entrants to sign down to a decision that depends only on later period profits and not those in the first period. With competition amongst record companies in a genre the optimal choice of $n_{g l}$ would also consider its impact on business-stealing from other competing record companies (see Appendix.) This is likely to lead to greater numbers of bands throughout the market and so to lessen, or even completely offset, the under-entry problem discussed. Consequently, the welfare consequences of local content requirements are likely to be more negative than in our analysis.

\section{ii. Faddists and enthusiasts.}

An alternative to our faddist/enthusiast distinction would be simply to posit a single type of consumer who draws their favorite band from the entire set of alternatives. Under the discrete choice model of record buying used here, the probability of a consumer buying the recording of band $j$ in genre $g$ would become: 


$$
x_{g j}=\frac{\exp \left\{a_{g j}\right\}}{\sum_{k=1}^{n_{g 1}} \exp \left\{a_{g k}\right\}+\sum_{i=1}^{N_{g s}} \exp \left\{a_{g i}\right\}}
$$

Such a change would make little or no difference to the qualitative results of our analysis, but would complicate the algebra significantly. Under our current separation, if all bands of one type receive the same airplay (e.g. absent any quota) then each has an equal market share. With this more general specification that is still the case, but the denominator of these market share expressions for each type of band depends on the airtimes of all the bands in the genre, domestic or foreign, new or successful. So an increase in the airtime devoted to successful domestic bands (the novel component of the new-music quota discussed above) will now directly impact the record sales of new domestic bands, independent of any effect on entry.

\section{iii. Technological change}

Our model is motivated by an industry structure that has prevailed for some decades in the commercial music business. With high fixed costs of recording and promoting artists, record companies fill an essential role of funding start-ups (new entrants), radio plays an essential role in bringing new recordings to consumers' attention and successful bands and record companies share, in some fashion, in both the proceeds from record sales and any other rents that might be generated by successful bands. In recent years, many things have changed in the way that music is commercialized and here we reflect briefly on how these changes might impact on our model. See Richardson and Wilkie (2013) for a more complete discussion. Our conclusion is that the quota analysis is robust to these changes wrought, particularly, by the internet.

Recent years have seen at least four significant and related developments in the music industry. First is a substantial reduction in the costs of recording and disseminating music. Second is the growth of electronic music downloading, both legal and otherwise. Third is a 
dramatic decrease in the importance of recording sales revenues for bands, compared to concert and related revenues. Fourth is the rise of internet radio and the role of internet services in the dissemination of new music.

The development of cheap software and hardware has made it easier for artists to run home studios and the use of social media is often perceived as reducing the costs of disseminating music. Simply reducing the fixed cost of recording and promotion, so long as artists cannot sidestep the record companies completely, has straightforward effects in our model, through the comparative statics of a change in $F$, and does nothing to affect the qualitative analysis of a quota. Note, too, that the empirical incidence of artists bypassing the record company model successfully is vanishingly small: because of the marketing services a record company provides, the vast majority of commercially successful artists still transact with record companies along the lines modeled here. ${ }^{22}$

The existence of new online distribution structures also has little impact on our qualitative analysis of the effects of a quota: it does not matter if distribution is through buying physical CDs at a shop (either online or not) or downloading an MP3. ${ }^{23}$ The explosion of illegal downloading could be significant insofar as it undermines the record company business model, but the structure of record companies has not much changed in the internet era and our analysis seems to apply equally to the current situation. ${ }^{24}$

\footnotetext{
${ }^{22}$ See Table 1 at p.671 of Connolly and Krueger (2006), which identifies the top earning 35 artists who toured the U.S. in 2002. All of these are affiliated with recording companies and most with the then major labels (Sony, Warner, BMG, EMI and Universal, or subsidiaries thereof.) More recently, Businesswire.com (2012) reports that in Nielsen Soundscan's 2011 Music Industry Report the four large record companies - Sony and BMG merged in 2004 - had a combined market share of $90 \%$ of sales of physical album sales in $2011,86 \%$ of sales of digital albums and $87 \%$ of sales of digital tracks. The residual shares are likely to be dominated by smaller record companies.

${ }^{23}$ Cowen (2008) notes that, in 2008, the most significant retailer of music in the U.S. was still Wal-Mart, although Apple's iTunes was second.

${ }^{24}$ Record companies have experienced declining revenues from the increase in downloading in recent years and we have seen a concomitant increase in so-called " 360 degree" contracts, in which record companies take shares of profit from non-record sale related activities of their artists. This is essentially built in to our analysis already, as we assume that all revenues generated by a band on contract, whether from record sales or not, accrue to its record company at first.
} 
Connolly and Krueger (2006) provide a thorough description of the economics of popular music and one of their main observations is that, for most modern artists, nonrecording related income is much more significant than income derived from the sales of recorded music. ${ }^{25}$ This has little impact on our analysis; it is an observation regarding the relative size of recording revenues and what we model as rents, a ratio that does not affect our results, so long as they are complementary ${ }^{26}$ in the sense that record sales are a necessary prerequisite to success as a touring artist.

In the abstract, the rise of internet radio means little for our analysis: whether a recording is heard on $\mathrm{AM} / \mathrm{FM}$ radio, a digital radio or streamed over the internet, so long as it feeds into the likely success of an artist then our analysis still applies. ${ }^{27}$ More significantly, though, internet radio threatens the very feasibility of the policy instrument we have analyzed here: the local content quota. The technology of radio broadcasts means that, for most national regulators, controlling the broadcasts of all stations within one's sovereign territory means controlling the lion's share of radio broadcasts heard by denizens of that country. ${ }^{28}$ But, for example, the ability of a Canadian regulator to control the content of a Californian internet radio station is effectively zero, unless the station is simply blocked completely. The

\footnotetext{
${ }^{25}$ They note that in 2003 recording sales in the US earned $\$ 11.8$ billion versus $\$ 2.1$ billion for concert ticket sales. They quote one band manager as saying that the top 10 per cent of artists make money selling records, but the rest go on tour (p.673.)

${ }^{26}$ See Connolly and Krueger (2006) p.687. Note, too, that the U.S. Billboard pop charts that document the "top" recordings of the week are constructed to reflect explicitly both the highest selling albums of the week and which tracks from those albums are aired most regularly on radio broadcasting.

${ }^{27}$ There is some evidence that radio airplay was, relatively recently, still a significant factor in the music purchasing decisions of consumers. French Music Bureau (2003) at p.67 notes that the two most significant factors influencing the decision to buy a new album in the U.K. in 2002 were "hearing tracks from it on the radio" and "already know hit from hit single".

${ }^{28}$ This clearly varies from country to country. It is far easier for Australia, for instance, to regulate what its citizens hear on the radio than for France, although language barriers reduce the temptation of French consumers to listen to, for example, German radio broadcasts. But outside of land-based radio broadcasts, it is unclear what a regulator can do. In Australia, Vizard (1999) expresses this pithily: "Do we have jurisdiction over offshore suppliers who beam in by Internet, phone and satellite? How do we force the Los Angeles news Internet provider to include content relevant to us? How do we mandate that the BBC international news service include Australian weather reports? Or that the Discovery Channel include a pack of Tasmanian Devils savaging a sparrow?"
} 
rise of new media for the circulation of music is, in our judgment, the most serious threat to the use of local content requirements in broadcasting, from a regulator's perspective.

Finally, our analysis supposes that consumers hear new music only through their radio listening (which is why radio airtime is critical for bands' success) and we have cited survey data that supports the importance of radio listening in this fashion (see fn. 27.) The development of internet radio services such as Pandora (www.pandora.com) changes this nexus, as they provide individualized playlists based on a consumer's listening patterns. Nevertheless, so long as consumers continue to have preferences over music listening as we have modeled here, a commercial provider still has the same incentive as radio stations in our model to provide playlists in that same ratio. ${ }^{29}$

\section{Conclusion}

This paper has presented a model of the recorded music industry, integrating the demand and supply sides through the modeling of consumers, radio stations, record companies and artists. The model has then been used to analyze the supply-side consequences of local music quotas imposed on broadcasters.

We show that a mild (just binding) quota will be welfare-improving in this model, as it induces a domestic record company to sign up more new bands and this is welfareimproving for consumers who gain from diversity. Nevertheless, the quota will induce an 'internationalization' of domestic music - what we dub the 'Canadian divas effect' - by inducing domestic entry primarily into genres most dominated by international artists. If the quota also requires that some increased proportion of new domestic music be played, we identify an additional welfare loss due to the distorted programming choices it induces from affected radio stations.

\footnotetext{
29 The main way in which services such as Pandora.com change the music market is in catering to preference heterogeneity across individual consumers. Our model has no heterogeneity within a genre.
} 
While the Appendix does discuss this matter, for tractability in this model we finesse the potentially significant issue of band quality: all bands here have the same probability of success (for a given amount of radio airtime.) So one possible negative welfare effect of a quota - quality downgrading as record companies sign up lower-quality bands in response to the quota on foreign music - is not a feature here.

We consider the central contributions of the paper to be, first, its more thorough analysis of the supply-side effects of (i.e. the responses of artists and record companies to) local content quotas in broadcasting than has been undertaken previously and, second, its development of an integrated model of this sector. We identify a new channel by which such a quota might raise welfare but also illustrate its possibly perverse effects on the diversity of domestic music. 


\section{References}

Acheson, K. and Maule, C. (1990), 'Canadian content rules: a time for reconsideration', Canadian Public Policy, 16, 284-297.

Acheson, K. and Maule, C. (2006), 'Culture in international trade', in V.A. Ginsburgh and D. Throsby (eds.), Handbook of the Economics of Art and Culture, Elsevier B.V., Amsterdam.

American University ICT Database (2001), 'IT Landscape in France'. Available at http://wwwl.american.edu/carmel/bb5414a/liberal.htm. Accessed March 242012.

Anderson, S. and Coate, S. (2005), 'Market provision of public goods: a welfare analysis', Review of Economic Studies, 72, 947-972.

Anderson, S. and de Palma, A. (1992), 'The logit as a model of product differentiation', Oxford Economic Papers, 44, 51-67.

Bala, V. and Long, N.V. (2005), 'International trade and cultural diversity with preference selection', European Journal of Political Economy, 21, 143-162.

Berry, S. and Waldfogel, J. (1999a), 'Free entry and social inefficiency in radio broadcasting', RAND Journal of Economics, 30, 397-420.

Berry, S. and Waldfogel, J. (1999b), 'Public radio in the United States: does it correct market failure or cannibalize commercial stations?', Journal of Public Economics, 71, 189-211.

Businesswire.com (2012), 'The Nielsen Company \& Billboard's 2011 Music Industry Report'. Available at http://www.businesswire.com/news/home/20120105005547/ en/Nielsen-Company-Billboard\%E2\%80\%99s-2011-Music-Industry-Report. Accessed 20/09/2012.

Coase, R. (1966), 'The economics of broadcasting and government policy', American Economic Review, 56, 440-447.

Connolly, M. and Krueger, A.B. (2006), 'Rockonomics: the economics of popular music', in V.A. Ginsburgh and D. Throsby (eds.), Handbook of the Economics of Art and Culture, Elsevier B.V., Amsterdam.

Cowen, T. (2008), 'Why everything has changed: the recent revolution in cultural economics', Journal of Cultural Economics, 32, 261-273.

Crampes, C. and Hollander, A. (1999), 'The regulation of audiovisual content: quotas and conflicting objectives.', Centre de Recherche sur les Transports, University of Montreal, Montreal, Canada.

Doyle, C. (1998), 'Programming in a competitive broadcasting market: entry, welfare and regulation', Information Economics and Policy, 10, 23-39.

Francois, P. and van Ypersele, T. (2002), 'On the protection of cultural goods', Journal of International Economics, 56, 359-369.

French Music Bureau (2003), The British music market in comparison with the French music industry, Insitution, London.

Gordon, P. and Meunier, S. (2001), 'Globalization and French cultural identity', French Politics, Culture \& Society, 19, 22-41.

Jacobsen, V. (2000), 'Local content regulation of New Zealand television', Arthur Andersen, Wellington, NZ.

Krugman, P. (1999), 'Enemies of the WTO: bogus arguments against the World Trade Organization' Slate. 
Mangani, A. (2003), 'Profit and audience maximization in broadcasting markets', Information Economics and Policy, 15, 305-315.

Mas-Colell, A. (1999), 'Should cultural goods be treated differently?', Journal of Cultural Economics, 23, 87-93.

Owen, B. and Wildman, S. (1992), Video Economics, Harvard University Press, Cambridge, MA.

Perona, M. (2010), 'How broadcasting quotas harm program diversity'MPRA, Munich.

Revel, J.-F. (2003), 'The anti-American obsession'The New Criterion, Foundation for Cultural Reviews, Inc., New York, NY.

Richardson, M. (2006), 'Commercial broadcasting and local content: cultural quotas, advertising and public stations', Economic Journal, 116, 605-625.

Richardson, M . and F. Stähler (2013), 'On the "uniform pricing puzzle" in recorded music', ANU Working Papers in Economics and Econometrics \#612, Australian National University, June 2013.

Richardson, M. and S. Wilkie (2013), 'Faddists, enthusiasts and Canadian divas: a model of the recorded music market.' Working Papers in Economics and Econometrics \#600, Research School of Economics, Australian National University, Canberra, Australia.

Rogers, R. and Woodbury, J. (1996), 'Market structure, program diversity and radio audience size', Contemporary Economic Policy, 14, 81-91.

Shiller, B. and Waldfogel, J. (2011), 'Music for a song: an empirical look at uniform pricing and its alternatives', The Journal of Industrial Economics, LIX, 630-660.

Vizard, S. (1999), 'Andrew Olle Media Lecture', Australian Broadcasting Corporation, Sydney, Australia. 


\section{APPENDIX}

\section{i. $\quad$ Radio broadcasting quotas in practice ${ }^{l}$}

In many countries, local content requirements in radio broadcasting are nearly as old as radio broadcasting itself. For example, the first Canadian radio station to broadcast regular programming - XWA/Montreal - went to air in 1919; in 1932 the Canadian Radio Broadcasting Commission (CRBC) was established to regulate and control all broadcasting in Canada and provide a national broadcasting service, determining the number, location and power of radio stations as well as the time that should be devoted to national and local programming.

The extent of local content requirement varies considerably - from $20 \%$ in New Zealand (since 2002), for example, through $35 \%$ in Canada to $80 \%$ in Nigeria $^{2}$ - and the definition of local content also varies. The Canadian MAPL system ${ }^{3}$ is perhaps the most explicit and generally requires that Canadian content satisfy two of the following requirements: M (music) the music is composed entirely by a Canadian; A (artist) - the music is, or the lyrics are, performed principally by a Canadian; $\mathrm{P}$ (production) - the musical selection consists of a live performance that is (i) recorded wholly in Canada, or (ii) performed wholly in Canada and broadcast live in Canada; L (lyrics) - the lyrics are written entirely by a Canadian. (By this reasoning, much of the music of Krugman's "Canadian divas" does not qualify as Canadian content.)

In Australia, by contrast, the requirement is simply that broadcasting, "consists of music performed by Australians" and, "where more than one performer is involved in a musical

\footnotetext{
${ }^{1}$ For a more comprehensive discussion of broadcasting content protection around the world in 2000, see Appendix F of Productivity Commission (2000).

2 See Letts (2003) at p.3.

3 See Canadian Radio-television and Telecommunications Commission (2009).
} 
performance, the musical items concerned shall be regarded as being performed by an Australian if the performance is predominantly by one or more Australians" where this appears to refer to Australian residents (Commercial Radio Australia (2011) §4.) ${ }^{4}$

A prominent set of local cultural content requirements is that of France. Originally implemented in $1996^{5}$ and reformed in 2000, it now requires radio stations (subject to some variations across formats) to broadcast a minimum of $40 \%$ music performed in French (or a regional language spoken in France) at least half of which must be devoted to new French artists.

\footnotetext{
${ }^{4}$ Following a High Court of Australia decision (High Court of Australia (1998)) with respect to content rules in TV broadcasting, it is likely that $\mathrm{NZ}$ artists can also be included in the Australian radio content quota under the auspices of the CER free trade agreement between the two countries.

${ }^{5}$ This is not inconsistent with the European single-market philosophy, which also specifies European-wide content. In 1989 the European Union implemented the ironically-named Television Without Frontiers directive protecting audio-visual content within Europe and noting that, "all broadcasts emanating from and intended for reception within the Community ... should respect the law of the originating Member State applicable to broadcasts intended for reception by the public in that Member State." See The Council of the European Communities (1989).
} 


\section{ii. $\quad$ The nature of band 'success'}

In the paper we assume that the number of successful bands is a known, deterministic function of the number of new entrants:

$$
n_{g 2}=f\left(n_{g 1}\right), \quad f(0)=0, f^{\prime} \in(0,1), f^{\prime \prime} \leq 0
$$

As only a fraction $h$ of period 2 successful bands go on to be successful bands off-contract in period 3, we have $n_{g 3}=h n_{g 2}=h f\left(n_{g 1}\right)$ so that the total number of successful bands in genre $g$ in any period is given in steady state by $N_{g s}=(1+h) f\left(n_{g 1}\right)+n_{g}{ }^{*}$. This approach is one in which the probability of success is entirely exogenous.

But, while there is doubtless some uncertainty in the future prospects of a band, the essence of 'success' is that a record company decides to retain a particular band on contract. Consequently, 'success' is endogenous and is essentially a decision made by the record company. So suppose that the record company can choose $n_{g 1}$, as we have assumed so far, but can then also choose $n_{g 2}$, almost independently. With everything as before, this means that the record company's problem becomes:

$$
\max _{\left\{n_{g 1}, n_{g 2}\right\}} \pi_{g}=k_{1}+k_{2} \frac{n_{g 2}}{\left\{(1+h) n_{g 2}+n_{g}^{*}\right\}}-n_{g 1} F_{1}-n_{g 2} F_{2} \text { s.t. } n_{g 2} \leq n_{g 1}
$$

It is clear from this that, as noted earlier, the record company would never choose any $n_{g l}$ in excess of one if it were looking only to its profits from new bands. The only thing that motivates a higher value is that it relaxes the constraint on $n_{g 2}$. It can be easily seen from this problem that the record company would never choose a value of $n_{g l}$ strictly in excess of its desired value of $n_{g 2}-$ i.e. the constraint will always bind - so, letting $n_{g l}=n_{g l} \equiv n$ for notational simplicity, its steady-state problem is simply: 


$$
\max _{\{n\}} \pi_{g}=k_{1}+k_{2} \frac{n}{\left\{(1+h) n+n_{g}^{*}\right\}}-n\left(F_{1}+F_{2}\right)
$$

This yields a FOC of :

$$
\frac{\{.\}-(1+h) n}{\left\{(1+h) n+n_{g}^{*}\right\}^{2}}=\frac{n_{g}^{*}}{\left\{(1+h) n+n_{g}^{*}\right\}^{2}}-\frac{\left(F_{1}+F_{2}\right)}{k_{2}}=0
$$

This is very similar to (16) in the paper and, indeed, the LHS of the FOC in (A3) is, as was (16), increasing in $k_{2}$ and decreasing in $F_{1}, F_{2}$ and $h$. Similarly, the derivative of (A3) wrt $n_{g}{ }^{*}$ again has the same sign as $\left(N_{g s}-2 n_{g}{ }^{*}\right)$. So all the results derived in the deterministic case already analyzed apply in the same fashion to this equally deterministic case.

A more interesting and realistic case is that where record companies might draw some inference on a band's innate 'quality' by observing their first period record sales and might then base its re-signing decision on this. So suppose that bands have some innate 'quality' (say $\theta$, drawn from some distribution on support $[0,1])$ unobservable to record companies but which affects their record sales. In particular, suppose that a consumer again places a value $v_{g j}$ on purchasing the recording of a band $j$ in genre $g$ but that this value now depends not only on the band's share of radio airtime, $a_{g j}$, the price of the recording $p$, and the random idiosyncratic component $\varepsilon_{g j}$, but also on the band's $\theta$ in the following manner: $v_{g j}=\theta_{g j} a_{g j}+\varepsilon_{g j}-p$. A band of quality $\theta$ now has an expected market share of:

$$
x_{g j}=\frac{\exp \left\{\theta_{g j} a_{g j}\right\}}{\sum_{k=1}^{n} \exp \left\{\theta_{g k} a_{g k}\right\}}
$$

where the denominator is summed to $n=n_{g 1}$ in the case of new bands and $n=N_{g s}$ in the case of successful bands. So now it is not the case that equal airtimes will lead to equal market shares. But, while record companies, ex hypothesi, cannot observe each $\theta_{j}$ directly, they can observe a contracted band's actual record sales in its first period and so draw an inference as to its $\theta$. The 
problem facing the record company is essentially that laid out in (21) except with this exponential ratio determining record sales:

$$
\begin{gathered}
\max _{\left\{n_{g 1}, n_{g 2}\right\}} \pi_{g}=k_{1}+k_{2} E\left(\frac{\exp \left\{\theta_{g j} a_{g j}\right\}}{\sum_{k=1}^{N_{g s}} \exp \left\{\theta_{g k} a_{g k}\right\}}\right)-n_{g 1} F_{1}-n_{g 2} F_{2} \\
\text { s.t. } n_{g 2} \leq n_{g 1}
\end{gathered}
$$

Now, even in the case where $\theta$ is distributed uniformly on $[0,1]$, this problem is largely intractable due to the Poisson binomial distribution of the term in expectations. So consider a more degenerate distribution: suppose that $\theta$ takes one of two values, $\theta_{H}$ or $\theta_{L}$ for $\theta_{H}>\theta_{L}$, where the probability of $\theta_{H} \equiv \rho$ and this is common knowledge. The interesting case here is where $\theta_{L}$ is sufficiently low that the record company would not wish to retain a band known to be of that type: if this were not true then the realization of $\theta$ is of no interest to the record company and it would wish to retain all initially signed bands: the problem collapses to that just analyzed in which $n_{g 2}=n_{g 1}$. Similarly, the problem is uninteresting if $\theta_{H}$ is so low that all successful bands fail to cover the record company's fixed costs. So we suppose that the distribution is such that a record company would wish to retain any band it knew to be of type $\theta_{H}$ and not re-sign any band it knew to be of type $\theta_{L}$. To be specific, we let $\theta_{L}=0$ and $\theta_{H}=1$.

Considering the program in (A5), we see again that the only consideration that would lead a record company to sign up more than one new band is its effect in relaxing the constraint on the number of successful bands and that, again, the record company would never wish to choose $n_{g 1}$ greater than its anticipated choice of $n_{g 2}$. So, in steady state, its problem comes down to choosing $n_{g 1}$ when the expected number of bands that will be retained after period 1 is just $n_{g 2}=\rho n_{g 1}$ and given that all retained bands will have $\theta=1$. Thus, if all airtimes are equal then each successful band has the same market share and the record company's problem becomes: 


$$
\max _{\left\{n_{g 1}\right\}} \pi_{g}=k_{1}+k_{2}\left(\frac{\rho n_{g 1}}{\left\{(1+h) \rho n_{g 1}+n_{g}^{*}\right\}}\right)-n_{g 1}\left(F_{1}+\rho F_{2}\right)
$$

This is directly isomorphic to the program in (21) and yields the same qualitative results.

In sum, we argue that the specification of 'success' in our earlier analysis can be altered quite significantly without changing the essential tenor of the results. 


\section{iii. Laissez-faire comparative statics}

By the SOC for $n_{g l}$ in (22), the sign of $d n_{g l} / d x$ is the same as that of $d^{2} \mathrm{E}\left(\pi_{g}\right) / \mathrm{d} n_{g l} \mathrm{~d} x$ for any parameter $x$. The LHS of the FOC is increasing in $k_{2}$ and is decreasing in $F_{1}, F_{2}$ and $h$, so the optimal number of new bands in a genre is decreasing in $F_{1}, F_{2}$ and $h$ and increasing in all elements of $k_{2}$ (i.e. increasing in $p, L, \varphi c_{g}, \lambda_{g}$ and $\left(1-\mu_{g}\right)$ ). The derivative of the FOC wrt $n_{g}{ }^{*}$ has the same sign as $\left(N_{g s}-2 n_{g}{ }^{*}\right)$. That is, the optimal number of domestic new bands in a genre is increasing in the number of foreign successful bands in the genre if and only if foreign bands constitute less than half of the total of successful bands in the genre in steady state.

Alternatively, the optimal $n_{g l}$ is increasing in $n_{g}{ }^{*}$ if and only if the number of foreign bands is less than the number of successful domestic bands, both on and off contract. 


\section{iv. Analytics of a simple quota}

Suppose that the airtime devoted to foreign bands is restricted in genre $g$ by a binding quota such that $\sum_{m=1}^{n_{g}^{*}} a_{g m}^{*}=Q$ where $Q$ is less than the laissez-faire choice by the radio station sans quota. We term this a 'simple' quota as it imposes no restrictions on the mix between new and successful domestic bands' airtime. The problem facing a radio station in this genre is unchanged and it will still choose $A_{g}$ and $A_{g s}$ exactly as before, as given in (18). But, given $n_{g}^{*}$, it must reduce the airtime per foreign band to meet the quota, to $a_{g}^{* Q}=\frac{Q}{n_{g}^{*}}$, and this, for given $n_{g s}$ and $n_{g s c}$, implies an increase in airtime per successful domestic band to $a_{g s}^{Q}=\left(A_{g s}-Q\right) /\left(n_{g s}+n_{g s c}\right)$.

From the analogue for successful bands of equation (2) we have, in the presence of a simple quota

$$
x_{g s j}=\frac{\exp \left\{\frac{A_{g s}-Q}{n_{g 2}(1+h)}\right\}}{\left[n_{g 2}(1+h) \exp \left\{\frac{A_{g s}-Q}{n_{g 2}(1+h)}\right\}+n_{g}^{*} \exp \left(\frac{Q}{n_{g}^{*}}\right)\right]}
$$

For given $n_{g 1}$ (and therefore $n_{g 2}$ ) differentiating (A7) yields: 


$$
\begin{gathered}
\left.\frac{d x_{g s j}}{d Q}\right|_{n_{g 1}}=\frac{-\frac{[.]}{n_{g 2}(1+h)} \exp \{.\}-\exp \{.\}\left(\exp \left(\frac{Q}{n_{g}^{*}}\right)-\exp \{.\}\right)}{\left[n_{g 2}(1+h) \exp \left\{\frac{A_{g s}-Q}{n_{g 2}(1+h)}\right\}+n_{g}^{*} \exp \left(\frac{Q}{n_{g}^{*}}\right)\right]^{2}} \\
=-\frac{\exp \{.\}}{[.]^{2}}\left(\frac{[.]}{n_{g 2}(1+h)}+\exp \left(\frac{Q}{n_{g}^{*}}\right)-\exp \{.\}\right) \\
=-\frac{x_{g s j}}{[.]}\left(\exp \{.\}+\frac{n_{g}^{*}}{n_{g 2}(1+h)} \exp \left(\frac{Q}{n_{g}^{*}}\right)+\exp \left(\frac{Q}{n_{g}^{*}}\right)-\exp \{.\}\right) \\
=-\frac{x_{g s j}}{[.]} \exp \left(\frac{Q}{n_{g}^{*}}\right)\left(\frac{N_{g s}}{n_{g 2}(1+h)}\right) \\
=-x_{g s j} x_{g}^{*}\left(\frac{n_{g}^{*}+n_{g 2}(1+h)}{n_{g 2}(1+h)}\right)<0
\end{gathered}
$$

Thus a fall in $Q$ (a tightening of the quota), leading to greater airtime for all successful domestic bands, leads to greater record sales.

The record company's steady state problem is, from (21) and (A7):

$$
\begin{aligned}
\max _{\left\{n_{g 1}\right\}} E\left(\pi_{g}\right)= & k_{1}+k_{2} f\left(n_{g 1}\right) x_{g s}-n_{g 1} F_{1}-n_{g 2} F_{2} \\
& =k_{1}+k_{2} \frac{f\left(n_{g 1}\right) \exp \left\{\frac{A_{g s}-Q}{(1+h) f\left(n_{g 1}\right)}\right\}}{\left[(1+h) f\left(n_{g 1}\right) \exp \{.\}+n_{g}^{*} \exp \left(\frac{Q}{n_{g}^{*}}\right)\right]}-n_{g 1} F_{1}-f\left(n_{g 1}\right) F_{2}
\end{aligned}
$$

The FOC for this problem is, dropping the argument of $f$ for clarity:

$$
k_{2}\left(f \frac{d}{d n_{g 1}}\left(x_{g s}\right)+f^{\prime} x_{g s}\right)-F_{1}-f^{\prime} F_{2}=0
$$

where $F \equiv F_{1}+f^{\prime} F_{2}>0$. But: 


$$
\begin{aligned}
\frac{d}{d n_{g 1}}\left(x_{g s}\right)= & \frac{1}{[.]^{2}}\left(-\exp \{.\}\{.\} f^{-1} f^{\prime}[.]\right. \\
& \left.-\exp \{.\}(1+h)\left(f^{\prime} \exp \{.\}-\exp \{.\}\{.\} f^{\prime}\right)\right) \\
& =\frac{\exp \{.\} f^{\prime}}{[.]^{2}}\left(-\{.\} f^{-1}[.]-(1+h) \exp \{.\}(1-\{.\})\right) \\
& =-x_{g s}\left(\{.\} f^{\prime} f^{-1}+(1+h) x_{g s}(1-\{.\})\right)
\end{aligned}
$$

where [.] and (.) represent the bracketed terms in (A9) and where we have also used the definition of $x_{g s}$ from that expression in simplifying. Accordingly, the FOC for $n_{g l}$ can be written as:

$$
\begin{aligned}
\Gamma \equiv-x_{g s}\{.\} f^{\prime} & -(1+h)\left(x_{g s}\right)^{2} f(1-\{.\})+f^{\prime} x_{g s}-\frac{F}{k_{2}} \\
& =x_{g s}\left(1-\left\{\frac{A_{g s}-Q}{(1+h) f}\right\}\right)\left(f^{\prime}-(1+h) f x_{g s}\right)-\frac{F}{k_{2}}=0
\end{aligned}
$$

Note that the expression in the curly bracket is a fraction less than one, so one minus that expression is positive. Thus the term $\left(f^{\prime}-(1+h) f x_{g s}\right)$ must also be positive. Denoting the LHS of this equation by $\Gamma$, from the firm's SOCs we know that the sign of $\mathrm{d} n_{g l} / \mathrm{d} Q$ is the same as that of $\mathrm{d} \Gamma / \mathrm{d} Q$. From (A7) we have 


$$
\begin{aligned}
\frac{d x_{g s}}{d Q} \equiv x_{Q}= & \frac{1}{[.]^{2}}\left(-\frac{1}{(1+h) f}[.] \exp \{.\}-\exp \{.\}\left(\exp \left(\frac{Q}{n_{g}^{*}}\right)-\exp \{.\}\right)\right) \\
& =\frac{x_{g s}}{[.]}\left(-\frac{1}{(1+h) f}[.]-\exp \left(\frac{Q}{n_{g}^{*}}\right)+\exp \{.\}\right) \\
& =\frac{x_{g s}}{(1+h) f[.]}\left(-(1+h) f \exp \{.\}-n_{g}^{*} \exp \left\{\frac{Q}{n_{g}^{*}}\right\}\right. \\
& \left.-(1+h) f \exp \left(\frac{Q}{n_{g}^{*}}\right)+(1+h) f \exp \{.\}\right) \\
& =\frac{x_{g s}}{(1+h) f[.]}\left(-n_{g}^{*}-(1+h) f\right) \exp \left\{\frac{Q}{n_{g}^{*}}\right\} \\
& =-\frac{N_{g s} x_{g s}}{(1+h) f[.]} \exp \left\{\frac{Q}{n_{g}^{*}}\right\}<0
\end{aligned}
$$

From (A12) the sign of $\mathrm{d} \Gamma / \mathrm{d} Q$ is the same as that of

$$
\begin{aligned}
\frac{d}{d Q}\left(x_{g s}(1-\right. & \left.\left.\left\{\frac{A_{g s}-Q}{(1+h) f}\right\}\right)\left(f^{\prime}-(1+h) f x_{g s}\right)\right) \\
& =\left(x_{Q}(1-\{.\})\left(f^{\prime}-2(1+h) f x_{g s}\right)+\frac{x_{g s}\left(f^{\prime}-(1+h) f x_{g s}\right)}{(1+h) f}\right)
\end{aligned}
$$

Suppose this is evaluated at the no-quota solution. At that point $x=1 / N_{g s}$ and $()=.\left(A_{g s} / N_{g s}\right)=\left(Q / n_{g}{ }^{*}\right)$. So

$$
\left.x_{Q}\right|_{\text {no quota }}=-\frac{x_{g s} \exp \{.\} N_{g s}}{\left[N_{g s} \exp \{.\}\right](1+h) f}=-\frac{x_{g s}}{(1+h) f}<0
$$

Then the sign of $\mathrm{d} \Gamma / \mathrm{d} Q$ is the same as that of 


$$
\begin{aligned}
& \frac{1}{(1+h) f}\left(-x_{g s}(1-\{.\})\left(f^{\prime}-2(1+h) f x_{g s}\right)+x_{g s}\left(f^{\prime}-(1+h) f x_{g s}\right)\right) \\
& =\frac{x_{g s}}{(1+h) f}\left(-(1-\{.\})\left(f^{\prime}-2(1+h) f x_{g s}\right)\right. \\
& \left.\quad+\left(f^{\prime}-(1+h) f x_{g s}\right)\right) \\
& =\frac{x_{g s}}{(1+h) f}\left(\{.\}\left(f^{\prime}-(1+h) f x_{g s}\right)-(1+h) f x_{g s}(\{.\}-1)\right)>0
\end{aligned}
$$

where the sign comes from the fact that $()<$.1 and $\left(f^{\prime}-(1+h) f x_{g s}\right)>0$.

That is, a tightening of the quota - a fall in $Q$ - evaluated at the no-quota solution will induce an increase in the number of new domestic bands. Thus in steady state there is an increase in new entrants that flows through to the number of successful domestic bands, both onand off-contract. 


\section{v. Welfare effects of simple quota}

From (A10), by the envelope theorem,

$$
\frac{d \pi_{g}}{d Q}=\frac{\partial \pi_{g}}{\partial Q}+\frac{\partial \pi_{g}}{\partial n_{g 1}} \frac{d n_{g 1}}{d Q}=k_{2} f\left(n_{g 1}\right) \frac{d x_{g s}}{d Q}<0
$$

So a tightening of the quota (a fall in $Q$ ) raises the profits of the domestic record company.

For enthusiast consumers we have, from (25),

$$
C S_{g e}=\mu_{g} \lambda_{g} L(T-p) \ln \left(n_{g 1} \exp \left(\frac{1}{n_{g 1}}\right)\right)
$$

The only impact of a reduction in $Q$ on such consumers is through the increase in $n_{g}$ that such a reduction induces. But

$$
\frac{d C S_{g e}}{d n_{g 1}}=\mu_{g} \lambda_{g} L(T-p) \frac{1}{n_{g 1}}\left(1-\frac{1}{n_{g 1}}\right)>0
$$

For faddist consumers we have, symmetrically,

$$
C S_{g f}=\left(1-\mu_{g}\right) \lambda_{g} L\left(T^{f}-p\right) \ln \left[n_{g}^{*} \exp \left(\frac{Q}{n_{g}^{*}}\right)+(1+h) f\left(n_{g 1}\right) \exp \left\{\frac{A_{g s}-Q}{(1+h) f\left(n_{g 1}\right)}\right\}\right]
$$

Thus:

$$
\frac{d C S_{g f}}{d Q} \frac{[.]}{\left(1-\mu_{g}\right) \lambda_{g} L\left(T^{f}-p\right)}=\frac{\partial[.]}{\partial Q}+\frac{\partial[.]}{\partial n_{g 1}} \frac{d n_{g 1}}{d Q}
$$

where the square bracket in (A20) refers to the square bracketed term in (A19). Differentiating the terms in $C S_{g f}$ yields:

$$
\begin{gathered}
\frac{\partial[.]}{\partial n_{g 1}}=(1+h)\left(f^{\prime} \exp \left\{\frac{A_{g s}-Q}{(1+h) f}\right\}-f \exp \left\{\frac{A_{g s}-Q}{(1+h) f}\right\} \frac{\{.\}}{f} f^{\prime}\right) \\
=(1+h) f^{\prime} \exp \{.\}(1-\{.\})>0 \\
\frac{\partial[.]}{\partial Q}=n_{g}^{*} \exp \left(\frac{Q}{n_{g}^{*}}\right) \frac{1}{n_{g}^{*}}-(1+h) f \exp \left\{\frac{A_{g s}-Q}{(1+h) f}\right\} \frac{1}{(1+h) f}=\exp \left(\frac{Q}{n_{g}^{*}}\right)-\exp \left\{\frac{A_{g s}-Q}{(1+h) f}\right\}
\end{gathered}
$$


This last expression is just $\exp \left(a_{g}{ }^{*}\right)-\exp \left(a_{g s}\right)$ and so is negative iff each domestic band gets more airtime, in equilibrium, than each foreign band. Clearly these two are equal when the quota is just binding and, if $n_{g l}$ were unchanged, then each domestic band would get strictly more airtime than each foreign band as the quota were tightened. However, a fall in $Q$ induces an increase in $n_{g 1}$, as discussed earlier, so the overall effect is not immediately obvious. But the signing of new bands by the record company in response to a tighter quota only occurs because of the increased profitability of successful bands and that profitability is a monotonic increasing function of airtime for successful bands. Hence it cannot be the case that entry is sufficient to reduce that airtime (and thus profitability.) All in all, the solution cum quota must be such that per-band airtime for successful domestic bands must be no lower than in the absence of any quota. Thus

$$
\begin{aligned}
\frac{d C S_{g f}}{d Q} \frac{\left[n_{g}^{*} \exp \left(\frac{Q}{n_{g}^{*}}\right)+(1+h) f \exp \left\{\frac{A_{g s}-Q}{(1+h) f}\right\}\right]}{\left(1-\mu_{g}\right) \lambda_{g} L\left(T^{f}-p\right)} \\
=\underbrace{\exp \left(\frac{Q}{n_{g}^{*}}\right)-\exp \left\{\frac{A_{g s}-Q}{(1+h) f}\right\}}_{(-)}+\underbrace{(1+h) f^{\prime} \exp \{.\}(1-\{.\})}_{(+)} \frac{d n_{g 1}}{d Q}
\end{aligned}
$$

and a sufficient condition for faddist consumers to gain from a quota (a reduction in $Q$ ) is that a tighter quota induces entry: $d n_{g l} / d Q<0$. This is certainly satisfied when the quota is just binding, as demonstrated above.

All in all, then, a just-binding quota is welfare-improving, benefitting record companies and both faddist and enthusiast consumers.

Combining these effects, 


$$
\begin{aligned}
\frac{d W_{g}}{d Q} \frac{1}{\lambda_{g} L}=- & \left(1-\mu_{g}\right)\left(p+\varphi c_{g}\right) f x_{g s j} x_{g}^{*}\left(\frac{n_{g}^{*}+n_{g 2}(1+h)}{n_{g 2}(1+h)}\right) \\
& +(T \\
& -p)\left[\frac{\mu_{g} \frac{1}{n_{g 1}}\left(1-\frac{1}{n_{g 1}}\right)+(1+h) f^{\prime} \exp \{.\}(1-\{.\})\left(1-\mu_{g}\right)}{\left[n_{g}^{*} \exp \left(\frac{Q}{n_{g}^{*}}\right)+(1+h) f \exp \left\{\frac{A_{g s}-Q}{(1+h) f}\right\}\right]}\right] \frac{d n_{g 1}}{d Q} \\
& -\frac{\left(1-\mu_{g}\right)(T-p)\left(\exp \left\{\frac{A_{g s}-Q}{(1+h) f}\right\}-\exp \left(\frac{Q}{n_{g}^{*}}\right)\right)}{\left[n_{g}^{*} \exp \left(\frac{Q}{n_{g}^{*}}\right)+(1+h) f \exp \left\{\frac{A_{g s}-Q}{(1+h) f}\right\}\right]}
\end{aligned}
$$




\section{vi. Multiple record companies in a genre}

Suppose that there are $R_{g}$ record companies that operate in genre $g$. The problem facing the typical record company, analogous to (21), is:

$$
\begin{aligned}
\max _{\left\{n_{g 1 i}\right\}} \pi_{g i}\left(n_{g 1 i}\right) & \\
= & \frac{n_{g 1 i}}{\sum_{k} n_{g 1 k}} k_{1}+k_{2} \frac{f\left(n_{g 1 i}\right)}{\left\{(1+h)\left[\sum_{k} f\left(n_{g 1 k}\right)\right]+n_{g}^{*}\right\}}-n_{g 1 i} F_{1}-f\left(n_{g 1 i}\right) F_{2}
\end{aligned}
$$

where $k_{1}=p L \mu_{g} \lambda_{g}$ and $k_{2}=\left(1-\mu_{g}\right)\left(p+\varphi c_{g}\right) \lambda_{g} L$ are the same positive constants as in the paper and $k$ indexes the $R_{g}$ record companies in the genre. This yields a FOC as follows:

$$
\begin{gathered}
\frac{d E\left(\pi_{g i}\right)}{d n_{g 1 i}}=\frac{\sum_{k \neq i} n_{g 1 k}}{\left(\sum_{k} n_{g 1 k}\right)^{2}} k_{1}+k_{2} \frac{f^{\prime}\left(n_{g 1 i}\right)\left(\{.\}-f\left(n_{g 1 i}\right)(1+h)\right)}{\left\{(1+h)\left[\sum_{k} f\left(n_{g 1 k}\right)\right]+n_{g}^{*}\right\}^{2}} \\
-\left(F_{1}+f^{\prime}\left(n_{g 1 i}\right) F_{2}\right) \\
=\frac{\sum_{k \neq i} n_{g 1 k}}{\left(\sum_{k} n_{g 1 k}\right)^{2}} k_{1}+k_{2} \frac{f^{\prime}\left(n_{g 1 i}\right)\left[(1+h) \sum_{k \neq i} f\left(n_{g 1 k}\right)+n_{g}^{*}\right]}{\{.\}^{2}} \\
-\left(F_{1}+f^{\prime}\left(n_{g 1 i}\right) F_{2}\right)=0
\end{gathered}
$$

In the symmetric equilibrium, however, $n_{g 1 i}=n_{g 1 k} \equiv n_{g 1}$ for all $k$, so $\sum_{k} n_{g 1 k}=R_{g}$ and $\sum_{k \neq i} n_{g l k}=R_{g}-1$ so this becomes:

$$
\begin{gathered}
\frac{d E\left(\pi_{g i}\right)}{d n_{g 1 i}}=\frac{\left(\mathrm{R}_{g}-1\right)}{\left(\mathrm{R}_{g}\right)^{2} n_{g 1}} k_{1}+k_{2} \frac{f^{\prime}\left(n_{g 1}\right)\left[(1+h)\left(\mathrm{R}_{g}-1\right) f\left(n_{g 1}\right)+n_{g}^{*}\right]}{\left\{(1+h) \mathrm{R}_{g} f\left(n_{g 1}\right)+n_{g}^{*}\right\}^{2}} \\
-\left(F_{1}+f^{\prime}\left(n_{g 1}\right) F_{2}\right)=0
\end{gathered}
$$

Of course, this collapses to (22) when $R_{g}=1$. But when there is more than one record company we pick up a new term in the FOC (A26) that is positive (albeit declining in $n_{g 1}$ ) and indicates that an increase in new band numbers for a record company provides a new source of additional 
profits, compared to the single company case, due to the increased share of first-period profits that it generates.

The SOC for the firm is, from (A25) and suppressing the arguments of $f($.$) :$

$$
\begin{aligned}
\frac{d^{2} E\left(\pi_{g i}\right)}{\left(d n_{g 1 i}\right)^{2}}= & -2 \frac{\sum_{k \neq i} n_{g 1 k}}{\left(\sum_{k} n_{g 1 k}\right)^{3}} k_{1}+k_{2}\left[(1+h) \sum_{k \neq i} f+n_{g}^{*}\right] \frac{f^{\prime \prime}\{.\}-2(1+h)\left(f^{\prime}\right)^{2}}{\left\{(1+h)\left[\sum_{k} f\right]+n_{g}^{*}\right\}^{3}} \\
& -f^{\prime \prime} F_{2} \\
& =2 \frac{\left(1-\mathrm{R}_{g}\right)}{\left(\mathrm{R}_{g}\right)^{3}} \frac{k_{1}}{\left(n_{g 1}\right)^{2}} \\
& +k_{2}\left[(1+h)\left(\mathrm{R}_{g}-1\right) f+n_{g}^{*}\right] \frac{f^{\prime \prime}\{.\}-2(1+h)\left(f^{\prime}\right)^{2}}{\left\{(1+h) \mathrm{R}_{g} f+n_{g}^{*}\right\}^{3}}-f^{\prime \prime} F_{2}<0
\end{aligned}
$$

Differentiating (A26) with respect to $R_{g}$ yields:

$$
\begin{aligned}
\frac{\partial}{\partial \mathrm{R}_{g}} \frac{d E\left(\pi_{g i}\right)}{d n_{g 1 i}} & =\frac{\left(2-\mathrm{R}_{g}\right)}{\left(\mathrm{R}_{g}\right)^{3}} \frac{k_{1}}{n_{g 1}} \\
& +k_{2} f^{\prime}\left(n_{g 1}\right) \frac{(1+h) f\left(n_{g 1}\right)\left[(1+h) f\left(n_{g 1}\right)\left(2-\mathrm{R}_{g}\right)-n_{g}^{*}\right]}{\left\{(1+h) \mathrm{R}_{g} f\left(n_{g 1}\right)+n_{g}^{*}\right\}^{3}}
\end{aligned}
$$

Clearly this is non-positive for $R_{g} \geq 2$, implying that each record company's optimal choice of new bands to sign is decreasing in the number of record companies in the genre. 


\section{References}

Canadian Radio-television and Telecommunications Commission (2009), 'The MAPL system defining a Canadian song', Ottawa, Canada.

Commercial Radio Australia (2011), 'Codes of Practice \& Guidelines'.

High Court of Australia (1998), 'Project Blue Sky Inc v Australian Broadcasting Authority'Commonwealth Law Reports, High Court of Australia.

Letts, R. (2003), The effects of globalisation on music in five contrasting countries, Insitution. Productivity Commission (2000), 'Broadcasting: Inquiry Report', in The Productivity Commission (ed.), AusInfo, Canberra, Australia.

The Council of the European Communities (1989), 'Council Directive ("Television without Frontiers")', in T.C.o.t.E. Communities (ed.) 89/552/EEC, Brussels, Belgium. 